\title{
Monogenic diabetes and pregnancy
}

\section{Abstract}

Monogenic diabetes is frequently mistakenly diagnosed as either type I or type 2 diabetes, yet accounts for approximately I-2\% of diabetes. Identifying monogenic forms of diabetes has practical implications for specific therapy, screening of family members and genetic counselling. The most common forms of monogenic diabetes are due to glucokinase (GCK), hepatocyte nuclear factor (HNF)-IA and HNF-4A, HNF-IB, m.3243A>G gene defects. Practical aspects of their recognition, diagnosis and management are outlined, particularly as they relate to pregnancy. This knowledge is important for all physicians managing diabetes in pregnancy, given this is a time when previously unrecognised monogenic diabetes may be uncovered with careful attention to atypical features of diabetes misclassified as type I, type 2, or gestational diabetes.

\section{Keywords}

Maturity-onset diabetes of the young (MODY), monogenic diabetes, mitochondrial diabetes, maternally inherited diabetes and deafness (MIDD)

\section{Introduction}

The molecular diagnosis of monogenic forms of diabetes is important because it enables genetic counselling, predictive genetic testing in affected families, personalised medication and information regarding prognosis to be provided. Furthermore, these monogenic conditions shed light into the pathophysiology of the more prevalent metabolic syndrome (previously reviewed ${ }^{1}$ ). This article will focus on the distinguishing clinical features and management of the most common monogenic causes of familial diabetes, with illustrative case histories. This knowledge is important for all physicians managing diabetes in pregnancy, given this is a time when previously unrecognised monogenic diabetes may be uncovered with careful attention to atypical features of diabetes misclassified as type 1, type 2, or gestational diabetes.

Diabetes is diagnosed by either elevated blood glucose or HbAlc values based on thresholds associated with a substantially increased risk of microvascular complications, particularly retinopathy among several cross-sectional epidemiology studies. ${ }^{2}$ The thresholds for diagnostic fasting blood glucose is $7.0 \mathrm{mmol} / \mathrm{L}(126 \mathrm{mg} / \mathrm{dL})$ or a $2 \mathrm{~h}$ blood glucose value after a $75 \mathrm{~g}$ oral glucose tolerance test of $11.1 \mathrm{mmol} / \mathrm{L}$ $(200 \mathrm{mg} / \mathrm{dL}) .{ }^{3} \mathrm{HbAlc}$ levels of $6.5 \%(48 \mathrm{mmol} / \mathrm{mol})$ or above are also diagnostic of diabetes. ${ }^{3}$ Unless there are classic symptoms of hyperglycaemia or there is an associated random plasma glucose of $200 \mathrm{mg} / \mathrm{dL}$ or above, then the test needs to be repeated to confirm a diagnosis of diabetes. ${ }^{3}$ Diabetes is classified into four clinical categories: type 1 diabetes (due to beta-cell destruction, leading to absolute insulin deficiency), type 2 diabetes (due to progressive insulin secretory defect on the background of insulin resistance), gestational diabetes (diabetes diagnosed during pregnancy that remits upon delivery) and other specific types of diabetes which include monogenic beta cell defects, genetic defects in insulin action, diseases of the exocrine pancreas and drug or chemical induced diabetes. Patients with type 1 diabetes typically present with hyperglycaemic symptoms of polyuria and polydipsia, and occasionally with diabetic ketoacidosis, with a clear requirement of insulin therapy to control glycaemia. Those with type 2 diabetes are frequently overweight, and typically respond to lifestyle changes, and various glucose lowering agents before requiring insulin therapy to control glycaemia. While all diabetes detected for the first time in pregnancy may be presumed to be gestational diabetes, a small proportion of these cases will subsequently require reclassification into type 1 diabetes, type 2 diabetes (either pre-existing or developing during pregnancy) or other types, based on failure to resolve post-partum. Difficulties in accurate classification of diabetes occur due to lack of cost-effective and reliable biomarkers of the underlying mechanistic defect in routine clinical practice and the epidemic of type 2 diabetes which accounts for approximately $95 \%$ of all patients with diabetes.
Monogenic beta-cell diabetes is thought to be responsible for approximately $2 \%$ of all diabetes cases diagnosed before the age of 45 years. ${ }^{4}$ Approximately $80 \%$ of cases are misdiagnosed as either type 1 or type 2 diabetes, reflecting lack of physician awareness and / or access to genetic testing. ${ }^{5}$ Clues to the diagnosis of monogenic forms of diabetes include lack of typical characteristics of type 1 diabetes (no pancreatic auto-antibodies, low or no insulin requirement five years after diagnosis, persistence of stimulated C-peptide $>200 \mathrm{pmol} / \mathrm{L}$, absence of diabetic ketoacidosis), or type 2 diabetes (lack of obesity, hypertension, dyslipidaemia), in the presence of a strong family history. ${ }^{4}$

\section{Glucokinase}

Those with a defect in one copy of their $G C K$ gene have fasting hyperglycaemia that is present from birth ${ }^{6}$ and show very little deterioration with age. ${ }^{7}$ The typical glucose abnormality consists of mild, fasting hyperglycaemia $(5.5-8 \mathrm{mmol} / \mathrm{L})$, small excursions with oral glucose tolerance testing or meals (usually below $3.5 \mathrm{mmol} / \mathrm{L})^{\mathbf{8}}$ and mild elevation in $\mathrm{HbAlc}(38-60 \mathrm{~mol} / \mathrm{L}){ }^{9}{ }^{9}$ These biochemical abnormalities in otherwise asymptomatic individuals could represent prediabetes, type 2 diabetes, incipient type 1 diabetes or in the case of pregnancy, gestational diabetes mellitus (GDM).

Prediabetes is defined as elevated fasting glucose above $5.5 \mathrm{mmol} / \mathrm{L}$, or $\mathrm{HbAlc}$ above $38 \mathrm{mmol} / \mathrm{mol}$, which tends to progress over time, and leads to type 2 diabetes once the threshold of fasting glucose of $7 \mathrm{mmol} / \mathrm{L}$ or $\mathrm{HbAlc}$ of $48 \mathrm{mmol} / \mathrm{mol}$ is reached. Type 2 diabetes is also generally progressive, requiring initially dietary modification, and subsequently one to several glucose lowering therapies, including insulin. Type 1 diabetes generally presents dramatically with osmotic symptoms and very rapid rise in blood glucose levels necessitating insulin therapy, and prompt failure of other glucose lowering medications if these are trialled in the first instance. Gestational diabetes is first recognised in pregnancy, and resolves after delivery.

In the absence of deterioration of mild hyperglycaemia with time or failure to resolve after delivery, and the presence of similarly stable,

Department of Medicine, Faculty of Medical and Health Sciences, University of Auckland, Auckland, New Zealand

\section{Corresponding author:}

Rinki Murphy, Department of Medicine, Faculty of Medical and Health Sciences, University of Auckland, Private Bag 92019, Auckland II42, New Zealand.

Email: R.Murphy@auckland.ac.nz 
mild, fasting hyperglycaemia in a first-degree family member, a significant proportion will have a heterozygous mutation in $G C K$, which is inherited in an autosomal dominant manner. Very often the affected parent remains under-diagnosed or has been misdiagnosed with early onset type 2 diabetes, so confirming the presence of mild, fasting glucose in one parent can be a helpful clue when considering a diagnosis of a GCK mutation.

Women with this glucose abnormality are often identified during routine screening for GDM and misclassified as such. However, unlike GDM, women with a $G C K$ defect have a stable derangement in their glucose metabolism, which does not resolve after delivery. Defects in GCK represent approximately $3 \%$ of Caucasian patients with gestational diabetes. ${ }^{10}$ The combination of BMI $<25 \mathrm{~kg} / \mathrm{m}^{2}$ and fasting glucose of $5.5 \mathrm{mmol} / \mathrm{L}$ or above, has been shown to have $68 \%$ sensitivity and $96 \%$ specificity for GCK. Using these criteria, the number of GDM women needed to test to find one case of GCK is 2.7. ${ }^{11}$

GCK is an enzyme that is considered the glucose sensor of beta cells, as it catalyses the rate-limiting step of glucose phosphorylation and therefore enables the pancreatic beta cell to respond by secreting insulin that is appropriate to the degree of glycaemia. ${ }^{12}$ An inactivating defect in one copy of the $G C K$ gene results in a slightly higher fasting glucose set-point for glucose regulation. However, if both copies of the $G C K$ gene are defective, then severe, permanent neonatal diabetes requiring insulin therapy results. ${ }^{13}$ This occurs in the rare circumstance where both parents have GCK diabetes (more likely in consanguineous couples), when the risk of having a child with permanent neonatal diabetes is $25 \%$, by inheriting two GCK mutations.

The clinical implication of confirming $G C K$-related diabetes is that it allows patients to be reassured that they have an inherited tendency to mild hyperglycaemia, which requires no specific glucose-lowering treatment or self-monitoring of blood glucose (outside of pregnancy), because microvascular or macrovascular complications are not expected. ${ }^{14,15}$ The near normal HbAlc in subjects with heterozygous $G C K$-related diabetes and lack of progression of hyperglycaemia are likely to explain the rarity of microvascular complications. ${ }^{16,17}$ In the Whitehall study, an increased risk of macrovascular disease was seen in patients with impaired glucose tolerance (IGT), so an increase might be expected in GCK subjects. ${ }^{18}$ However, in contrast to IGT and prediabetes, patients with GCK mutations have normal fasting lipids, ${ }^{16}$ are not significantly insulin resistant ${ }^{19}$ and have less post-prandial hyperglycaemia. ${ }^{20,21}$

In pregnant women with $G C K$, the need to reduce maternal blood glucose to minimise fetal risk of macrosomia depends on the fetal $G C K$ genotype, which will influence the fetus' sensing of maternal glucose. In $50 \%$ of cases, the fetus will not inherit the $G C K$ mutation and will respond to maternal hyperglycaemia by excess insulin production and therefore excess growth (by approximately $550-700 \mathrm{~g}$ ). Alternatively, if the fetus does inherit the $G C K$ abnormality it will sense the maternal hyperglycaemia as normal, produce normal amounts of insulin and have normal growth. ${ }^{22,23}$ In this latter setting, aggressively lowering maternal glycaemia may adversely affect fetal growth. ${ }^{24}$ As it is not currently possible to determine the fetal genotype non-invasively during pregnancy, decision on whether to treat maternal hyperglycaemia is made on the basis of monitoring fetal abdominal circumference and $>75^{\text {th }}$ percentile being the recommended threshold to start insulin and normalise maternal glycaemia. ${ }^{25}$ Fetal genotyping using cell-free fetal DNA from maternal plasma sampling during early pregnancy is currently being developed and may assist in appropriate glucose lowering therapy in women with $G C K$ during pregnancy only when the fetus does not carry the GCK mutation.

\section{Case I: GCK related diabetes - Unnecessary therapy}

Sue was diagnosed with "type 2 diabetes" at the age of 24 years during routine investigation for medical insurance purposes. Her fasting glucose was measured as $7.1 \mathrm{mmol} / \mathrm{L}$ and repeated at $7.2 \mathrm{mmol} / \mathrm{L}$. She had a body mass index (BMI) of $20 \mathrm{~kg} / \mathrm{m}^{2}$ and was otherwise healthy.
After being advised to make lifestyle modifications metformin was started. While her BMI reduced to $18 \mathrm{~kg} / \mathrm{m}^{2}$ a year later, her HbAlc was noted to be consistently $51-52 \mathrm{mmol} / \mathrm{mol}$ and gliclazide $80 \mathrm{mg}$ twice daily was added. Gliclazide was replaced with insulin when Sue became pregnant eight years later at the age of 36 years. She was treated with 54 units per day of insulin in the third trimester. Fetal growth scans showed normal growth with abdominal circumference just below the 50th percentile. She delivered a healthy baby girl with birthweight $2.8 \mathrm{~kg}$ at term. Post-partum, Sue was referred to the diabetes clinic where the diagnosis of a heterozygous GCK mutation was suspected. Her glutamic acid decarboxylase (GAD) and islet antigen 2 (IA2) antibodies were negative. She had no clinical features of insulin resistance with normal blood pressure $104 / 64 \mathrm{~mm} / \mathrm{Hg}$, normal lipids and no microvascular complications of diabetes. She had a strong family history of diabetes, affecting her mother (Lyn), her maternal uncle (Ron) and her maternal grandmother (see Figure 1). A heterozygous missense mutation in $G C K$ gene was identified in Sue. Cascade testing of other affected family members (Lyn and Ron) confirmed this was also the aetiology of their diabetes. Sue, Lyn and Ron were each able to discontinue their glucose lowering therapies without impact on their respective glycaemia status. Predictive testing of Sue's daughter showed the presence of GCK, so in retrospect, insulin treatment during this pregnancy was not necessary.

\section{HNF-IA}

In subjects with hepatocyte nuclear factor $(H N F) 1 A$ mutations, frank diabetes usually develops in adolescence or early adult life. The youngest age of onset of $H N F-1 A$ diabetes reported is four years, with $63 \%$ of patients having developed diabetes by the age of $25,94 \%$ by age 50 and $99 \%$ by age $75 .{ }^{26}$ In HNF1A mutation carriers, the fasting plasma glucose is initially normal, with elevated post-prandial glucose values, before developing severe hyperglycaemia in both fasting and postglucose load states. ${ }^{21}$ While most cases are misdiagnosed as type 1 diabetes and started on insulin, features such as low insulin dose requirement, the absence of diabetic ketoacidosis despite periods without insulin and three generation family history of diabetes are clues for $H N F-1 A$ diabetes. In this case further tests to check for the persistence of C-peptide, absent pancreatic and GAD auto-antibodies ${ }^{27}$ should be sought. If these criteria are present, then the prevalence of $H N F-1 A$ is approximately $10-20 \%{ }^{28}$

Additional biomarkers suggestive of $H N F-1 A$ diabetes include low levels of highly-sensitive (hs) C-reactive protein (CRP) ${ }^{29}$ and high levels of high-density lipoprotein (HDL) ${ }^{30}$ which are helpful to use in combination with other clinical characteristics. A measurement of hsCRP below $0.75 \mathrm{mg} / \mathrm{L}$ has been reported to show modest $79 \%$ sensitivity and $70 \%$ specificity for distinguishing between $H N F-1 A$ and type 2 diabetes. ${ }^{31}$ Elevated plasma HDL $>1.12$ has been reported to be $75 \%$ sensitive and $64 \%$ specific for $H N F-1 A$ diabetes. ${ }^{30}$

$H N F-1 A$ patients, like the $H N F-1 a$ knockout animals, are characterized by a low renal threshold and hence glycosuria. ${ }^{32-34}$ Renal glycosuria has been shown to precede the development of diabetes and makes diabetes screening by urinary screening for glycosuria an appropriate and sensitive screening test for family members who have had a positive predictive genetic test for $H N F-1 A .^{35}$

The patterns of microvascular complications are similar to that seen in type 1 diabetes, ${ }^{36}$ therefore it is important to strive for good glycaemic control. HNF1A mutation carriers are at increased risk of cardiovascular mortality despite having a protective appearing lipid profile. ${ }^{37}$ Statin therapy is recommended for $H N F 1 A$ mutation carriers by the age of 40 years.

The clinical implication of making a diagnosis of $H N F-1 A$ diabetes is that this can frequently be treated with low dose oral sulfonylurea (SU) therapy. ${ }^{38}$ Sulphonylureas (SU) bind to the sulfonylurea receptor subunit (SUR1) of the ATP-sensitive $\mathrm{K}^{+}\left(\mathrm{K}_{\mathrm{ATP}}\right)$ channel in the pancreatic beta cell and cause channel closure, allowing rise of the beta cell membrane potential, triggering opening of voltage-gated $\mathrm{Ca}^{2+}$ entry 


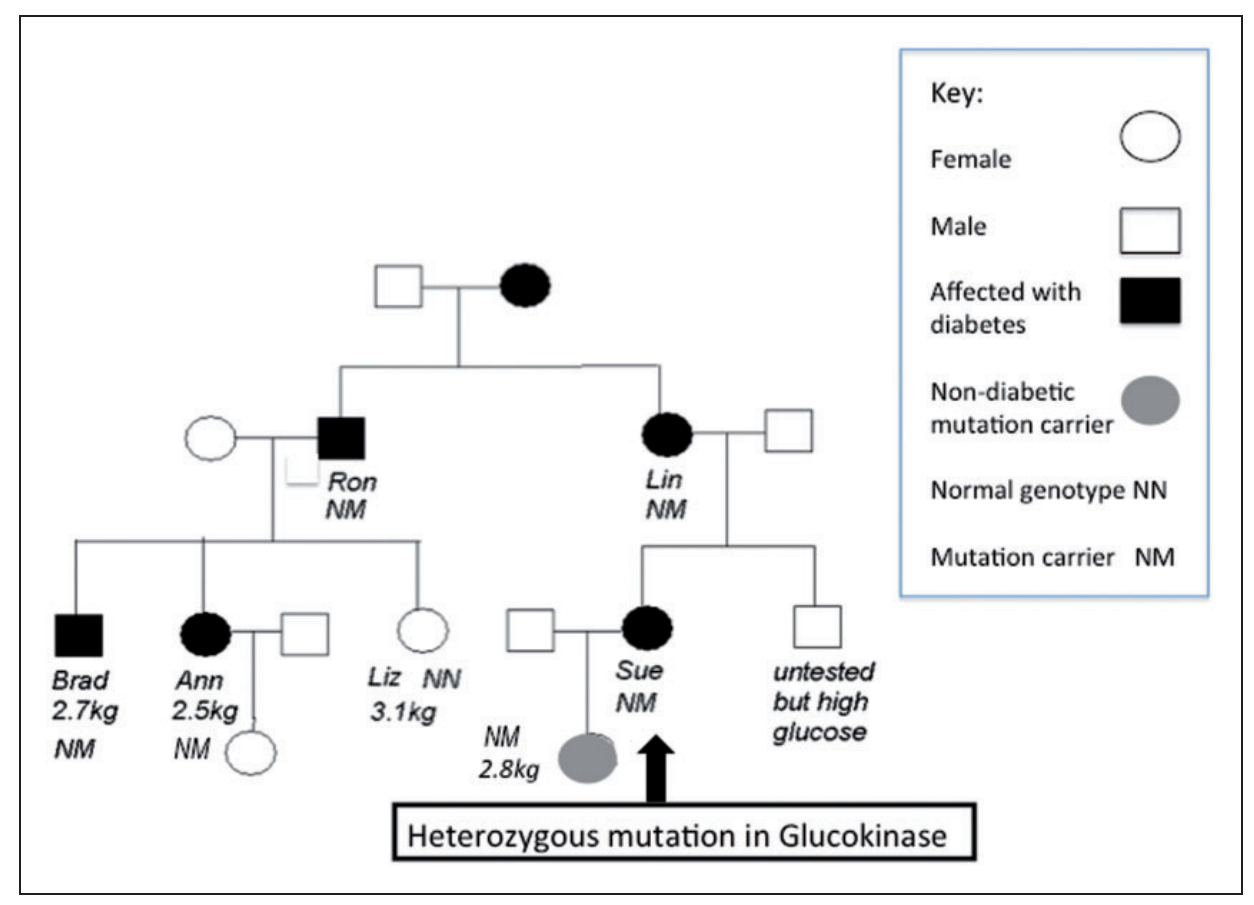

Figure I. Sue's family pedigree following genetic diagnosis of GCK mutation. The proband Sue indicated with an arrow was diagnosed with GCK first. Following this genetic diagnosis, other affected family members chose to have a genetic test. GCK mutations were found in her mother Lin, uncle Ron and cousins Brad and Ann. Sue's baby also had a predictive genetic test and was found to carry the GCK mutation.

and stimulation of insulin release. The action of SU therefore bypasses the major beta-cell defect arising from reduced $H N F-1 A$ function. Consequently, patients misdiagnosed as type 1 diabetes and treated with insulin can be switched to low-dose oral SU therapy once the genetic diagnosis of $H N F-1 A$ diabetes is made ${ }^{39}$ with the majority expressing great relief at being insulin-free. ${ }^{40}$ Glibenclamide treatment is recognised as safe in pregnancy, and given the superior and more stable control obtained by SU therapy, women generally choose to remain on this therapy rather than switch to insulin during pregnancy. Good control may be maintained for many years, although eventually some patients progress on to insulin treatment. Adjunctive treatment with oral DPP4 inhibitors has also been reported. ${ }^{41,42}$

HNF1A mutations may also predispose to familial liver adenomatosis through somatic inactivation of the remaining wild-type allele. ${ }^{43}$ Patients with liver adenomatosis are at risk of haemorrhage and malignant transformation, however, the role of systematic screening of all patients with $H N F-1 A$ with liver ultrasound is unclear.

\section{Case 2: HNF-IA diagnosis leads to change of therapy}

A 22-year-old woman Erin was diagnosed with type 1 diabetes at the age of 22 years when she presented with fatigue and urinary tract infection and was found to have an elevated random blood glucose of $17 \mathrm{mmol} / \mathrm{L}$. She was commenced on insulin but was not convinced, she needed to take it, and was insulin-free for over two years. Her brother, mother and maternal grandmother also had insulin treated diabetes (Figure 2). Upon presentation to the diabetes clinic she had HbAlc $75 \mathrm{mmol} / \mathrm{mol}$ which had deteriorated from a level of 57 two years earlier. Her BMI was $22 \mathrm{~kg} / \mathrm{m}^{2}$, her BP was normal at $124 / 82$. Her fasting capillary glucose levels were 5-7 and her post-prandial tests were 15-18. GAD and islet cell antibody tests were negative. She had elevated $\mathrm{HDL}$ at $1.5 \mathrm{mmol} / \mathrm{L}$ and undetectable level of CRP $(<1)$. Genetic testing found a mutation in HNF1A. This information enabled both Erin and her brother to stop taking insulin and to take gliclazide $40 \mathrm{mg}$ once daily with improvement in glycaemic control to $55 \mathrm{mmol} / \mathrm{L}$. Two of her brother's children also received pre-symptomatic genetic testing after genetic counselling. A positive result in one means this child can be monitored for glycosuria so that diabetes is diagnosed promptly and SU tablet commenced appropriately.

Erin went on to have a normal pregnancy after receiving genetic counselling that she had a $50 \%$ chance of passing on the HNF1A gene to her child. She was switched to glibenclamide $2.5 \mathrm{mg}$ daily, and remained on this therapy during her pregnancy without complications of hyperglycaemia or hypoglycaemia. She had an uneventful delivery of a healthy baby girl at term. She chose not to have predictive genetic testing of her daughter.

\section{HNF-4A}

$H N F-4 A$ related diabetes is less common than $H N F-1 A$, and results in a similar diabetic phenotype. In contrast to $H N F-1 A$ where there is no clinical manifestation at birth, HNF4A mutations can also cause neonatal hyperinsulinaemic hypoglycaemia. Approximately $50 \%$ of babies with HNF4A mutations are macrosomic (average increase in birth weight of $790 \mathrm{~g}$ compared with non-mutation carrying family members), suggesting increased insulin secretion in utero. ${ }^{44}$ The neonatal hyperinsulinaemic hypoglycaemia is variable in severity and duration, with some patients requiring diazoxide therapy for several years. ${ }^{45}$ Children with macrosomia and transient neonatal hypoglycaemia born to non-diabetic mothers should lead to evaluation of possible diabetes in the father and his family members. This is because both the father and the child may harbour unsuspected HNF4A mutation causing the macrosomia and transient neonatal hypoglycaemia phenotype, with development of diabetes in adolescence or early adulthood.

Reduced renal threshold for glucose is not observed in patients with $H N F-4 A$ and the biomarkers of reduced hsCRP and elevated HDL are not helpful in discriminating $H N F-4 A$ from type 2 diabetes. 


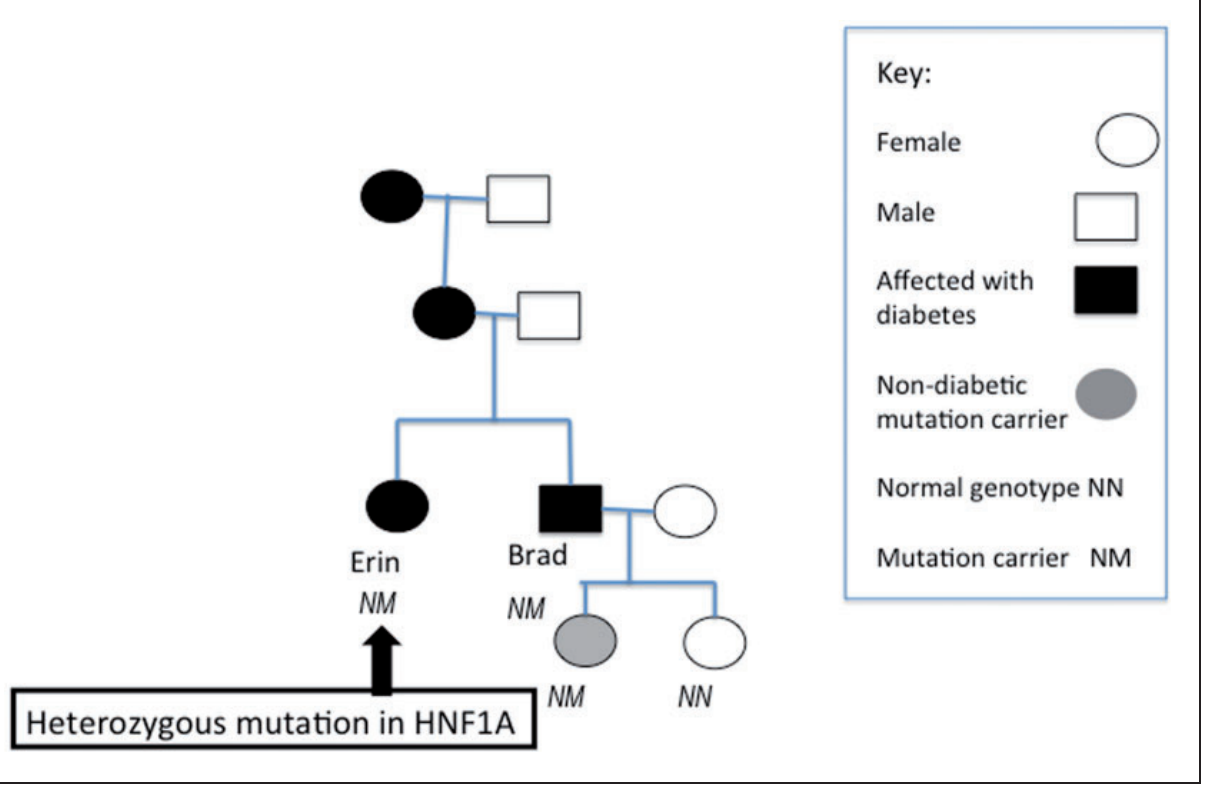

Figure 2. Erin's family pedigree following genetic diagnosis of HNFIA mutation.

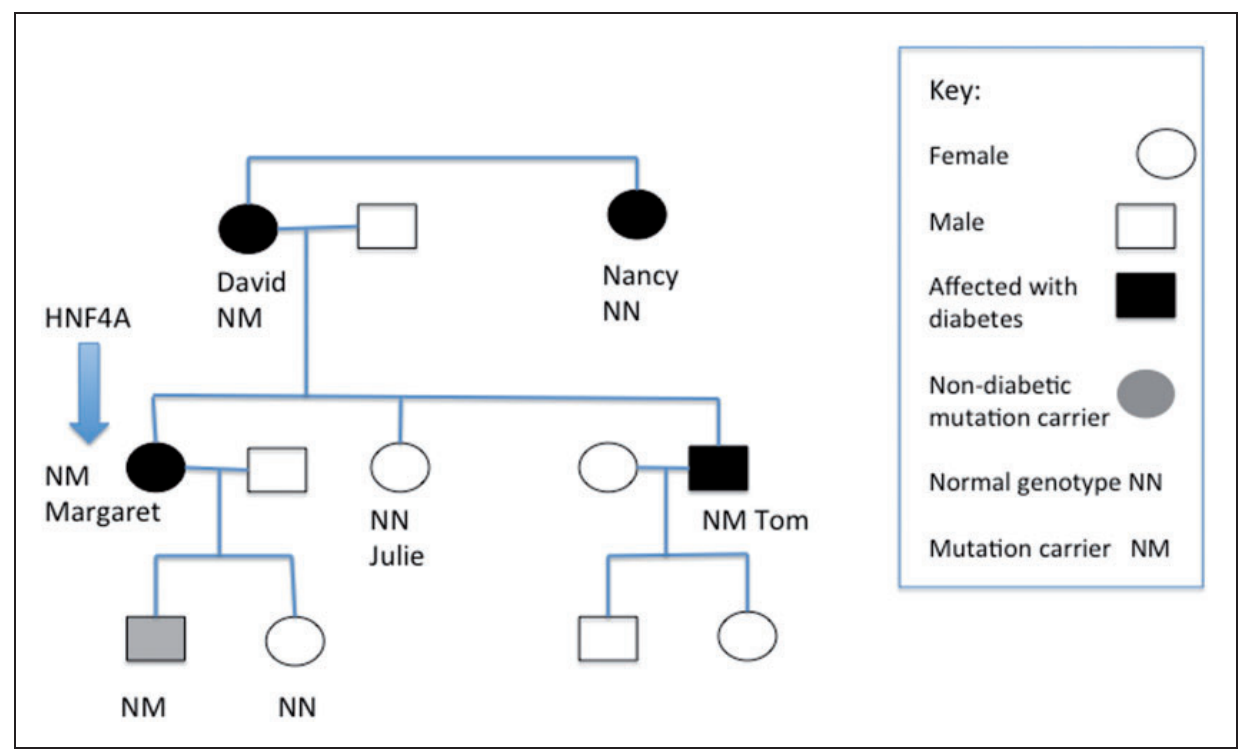

Figure 3. Margaret's family pedigree following genetic diagnosis of HNF4A mutation.

Making a genetic diagnosis of $H N F-4 A$ (like $H N F-1 A$ ) enables patients to be treated with oral SU therapy.

\section{Case 3: HNF-4A diagnosis leads to change in therapy}

Margaret was diagnosed with "type 2 diabetes" at the age of 16 years. She had a BMI of $23 \mathrm{~kg} / \mathrm{m}^{2}$ and normal lipids and blood pressure. She was treated with diet, metformin and then glibenclamide was added, until her first pregnancy at the age of 30 years. Glibenclamide was changed to insulin and she required approximately 60 units per day during her last trimester. She achieved HbAlc $50-60 \mathrm{mmol} / \mathrm{mol}$ during her pregnancy and delivered a healthy daughter by elective cesarean section at 38 weeks gestation with birthweight $3.9 \mathrm{~kg}$ at 38 weeks $(+2.2$ standard deviation score 


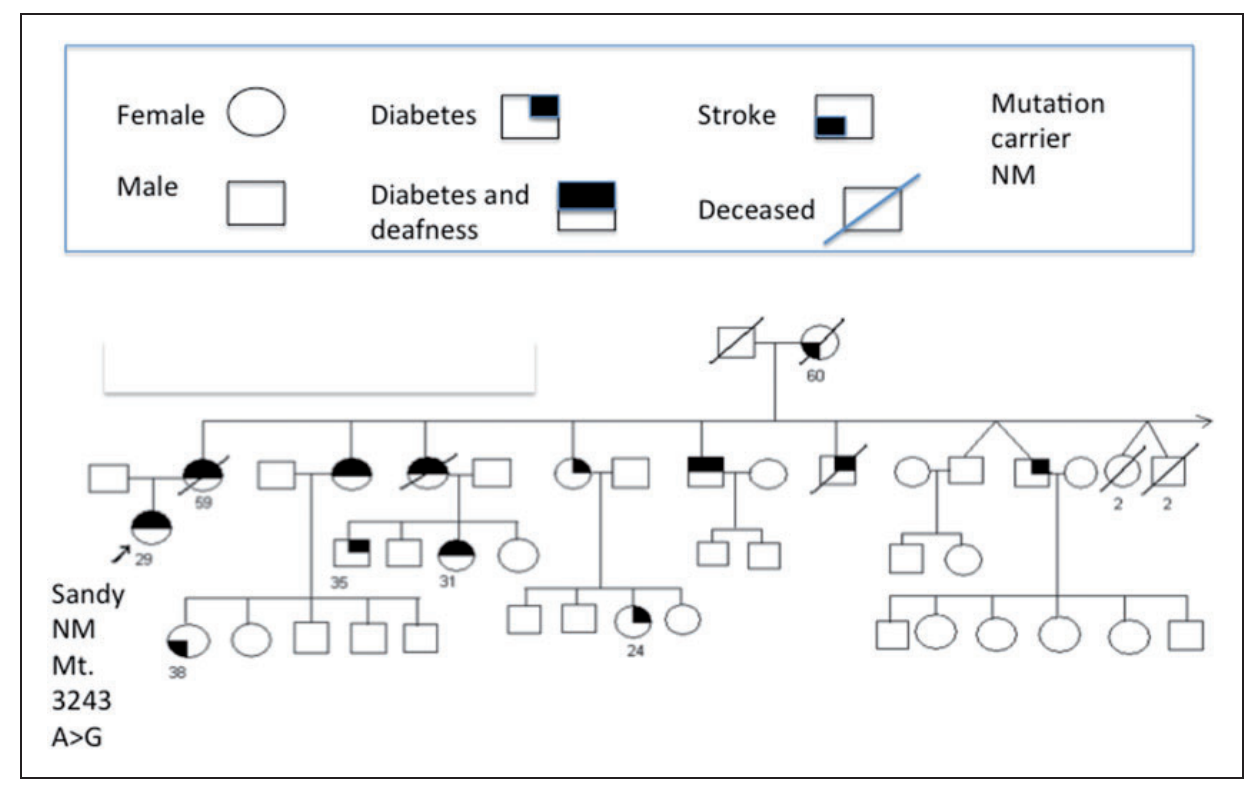

Figure 4. Sandy's family pedigree following genetic diagnosis of mt.3243A $>$ G mutation. The proband Sandy is indicated with an arrow. The age of each family member is shown below their square or circle symbol corresponding to male or female gender, respectively. Only Sandy was genetically tested and confirmed as being a mutation carrier (NM), while all her maternal family members were presumed to be obligate carriers of this mitochondrial point mutation.

\section{HNF-IB}

Mutations or deletions affecting the $H N F 1 B$ gene is a frequent cause of renal developmental disorders and diabetes, and is identified in $25 \%$ of such patients. ${ }^{46,47}$ It is a less common cause of familial diabetes without renal disease. The most common renal manifestation is renal cysts, but renal dysplasia, single kidney and horseshoe kidneys have also been described. Genital tract malformations in combination with renal tract abnormalities such as bicornuate uterus, uterus didelphis, rudimentary uterus and vaginal atresia, have also been described. However, $H N F-1 B$ defects are not a frequent cause of women with isolated uterine abnormalities. ${ }^{48}$ In addition, liver enzyme abnormalities, gout and pancreatic exocrine dysfunction may be seen, in keeping with the role of $H N F-1 B$ as a widely expressed transcription factor which plays a critical role in embryonic development of the kidney pancreas, liver and Mullerian duct. ${ }^{47}$

Women with diabetes, who are also known to have renal tract and genital tract abnormalities should be screened for a deletion or mutation in $H N F 1 B$ gene. Identifying $H N F-1 B$ in patients allows vigilance for associated features and genetic counselling regarding transmission to $50 \%$ of offspring. Diabetes generally requires insulin therapy.

\section{$m .3243 A>G$}

The prevalence of $m .3243 A>G$ point mutation affecting mitochondrial DNA is estimated at around $1 \%$ of unselected population with diabetes. ${ }^{49}$ The diabetes is most frequently associated with deafness and maternal family history of transmission from affected mothers to most offspring, but no transmission from affected fathers, hence the terminology "maternal inherited diabetes and deafness" (MIDD). The m.3243A $>G$ mutation can also cause more severe manifestations such as mitochondrial encephalopathy, lactic acidosis and stroke-like episodes (MELAS) in some family members. Most affected members have short stature and slim body habitus. ${ }^{49}$

Genetic testing for $m .3243 A>G$ point mutation is more sensitive when performed on buccal samples or urine rather than blood samples. $^{50,51}$
The clinical implications of making this genetic diagnosis include genetic counselling of individuals so that fathers can be reassured they will not transmit this to their offspring, while female members are likely to do so. The treatment implications include supplementation with thiamine and coenzyme Q10 52 and avoidance of metformin due to a theoretical risk of inducing lactic acidosis. ${ }^{49}$ Women with mitochondrial mutations have been reported to have excess miscarriages and preterm labour. ${ }^{53}$ Magnesium sulphate toxicity has been reported when given as tocolysis to a woman with MIDD. ${ }^{54}$

\section{Case 4: MIDD diagnosis leads to change of therapy}

Sandy was diagnosed with "type 2 diabetes" at the age of 36 years when she was found to have HbAlc of 65 . She was short and slim (height $1.55 \mathrm{~m}$ and weight $42.4 \mathrm{~kg}$, BMI 17.6). She also had hearing loss since 22 years of age and wore bilateral hearing aids. She had a very strong family history of diabetes (Figure 4). She was advised to make lifestyle changes, including modifying her diet and to increase her physical activity. She became exhausted after $1 \mathrm{~h}$ exercise sessions and developed prolonged muscle cramps. Retinal screening revealed pigmentary changes but no retinopathy or diabetic maculopathy. Genetic screening of a buccal swab showed the presence of $m .3243 A>G$. She was treated with low dose SU, thiamine and coenzyme Q10 supplementation.

\section{Conclusion}

While the majority of diabetes first diagnosed in pregnancy will be gestational diabetes, or pre-existing type 1 or type 2 diabetes, knowledge of monogenic diabetes will help to correctly diagnose those who have atypical features. Taking an accurate family history is important, given that autosomal dominant family history of diabetes may be caused by monogenic disruption of GCK, HNF-1A, HNF-4A or $H N F-1 B$. Those with a family history of MIDD may have inherited a mitochondrial point mutation $(m .3243 A>G)$. Consider the diagnosis of MIDD in the slim, short, deaf person with diabetes. Stable, mild, 
fasting hyperglycaemia without a history of microvascular complications suggests $G C K$. Atypical features of type 1 diabetes include history of low insulin dose requirement, the absence of diabetic ketoacidosis despite periods without insulin and three generation family history of diabetes. In this case, persistence of C-peptide, and absence of pancreatic and GAD auto-antibodies should be checked, which would suggest genetic defects affecting $H N F-1 A$ or $H N F-4 A$. The presence of biomarkers such as elevated HDL and low hsCRP is a clue for $H N F$ $1 A$, while the additional history of macrosomia and transient neonatal hypoglycaemia in affected individuals are clues for $H N F-4 A$ defect. Women with diabetes, who are also known to have renal tract and genital tract abnormalities should be screened for a deletion or mutation in $H N F 1 B$ gene.

Making a genetic diagnosis is important, as these subtypes have distinct management implications from more common forms of disease. Those with $G C K$ usually require no glucose lowering therapy, outside of pregnancy. In pregnancy, insulin therapy is required in $50 \%$ cases, when the baby's growth is observed to be increased, indicating that the baby's genotype is wild-type. Those with $H N F$ $1 A$ and $H N F-4 A$ are generally best treated with oral SU therapy, often with increased sensitivity. Those with $H N F-1 B$ require insulin therapy as oral glucose lowering therapies are generally not efficacious or durable, and in those with MIDD, metformin therapy is not recommended due to theoretical concerns of increased lactic acidosis.

\section{Declaration of conflicting interests}

The author(s) declared no potential conflicts of interest with respect to the research, authorship, and/or publication of this article.

\section{Funding}

RM is a University of Auckland funded clinician scientist.

\section{Ethical approval}

Not applicable.

\section{Guarantor}

RM

\section{Contributorship}

RM wrote the manuscript.

\section{References}

1. Murphy R, Carroll RW and Krebs JD. Pathogenesis of the metabolic syndrome: insights from monogenic disorders. Mediators Inflamm 2013; 2013: 920214.

2. Colagiuri S, Lee CM, Wong TY, et al. Glycemic thresholds for diabetes-specific retinopathy: implications for diagnostic criteria for diabetes. Diabetes Care 2011; 34: 145-150.

3. Standards of medical care in diabetes-2014. Diabetes Care 2014; 37 : S14-S80.

4. Murphy R, Ellard S and Hattersley AT. Clinical implications of a molecular genetic classification of monogenic beta-cell diabetes. Nat Clin Pract Endocrinol Metab 2008; 4: 200-213.

5. Shields BM, Hicks S, Shepherd MH, et al. Maturity-onset diabetes of the young (MODY): how many cases are we missing? Diabetologia 2010; 53: 2504-2508.

6. Prisco F, Iafusco D, Franzese A, et al. MODY 2 presenting as neonatal hyperglycaemia: a need to reshape the definition of "neonatal diabetes"? Diabetologia 2000; 43: 1331-1332.

7. Hattersley AT. Maturity-onset diabetes of the young: clinical heterogeneity explained by genetic heterogeneity. Diabet Med 1998; 15: $15-24$.
8. Byrne MM, Sturis J, Clement K, et al. Insulin secretory abnormalities in subjects with hyperglycemia due to glucokinase mutations. J Clin Investig 1994; 93: 1120-1130.

9. Steele AM, Wensley KJ, Ellard S, et al. Use of HbAlc in the identification of patients with hyperglycaemia caused by a glucokinase mutation: observational case control studies. PloS One 2013; 8: e65326.

10. Ellard S, Beards F, Allen LIS, et al. A high prevalence of glucokinase mutatiions in gestational diabetic subjects selected by clinical criteria. Diabetologia 2000; 43: 250-253.

11. Chakera AJ, Spyer G, Vincent N, et al. The $0.1 \%$ of the population with glucokinase monogenic diabetes can be recognized by clinical characteristics in pregnancy: the Atlantic Diabetes in Pregnancy cohort. Diabetes Care 2014; 37(5): 1230-1236.

12. Matschinsky F, Liang Y, Kesavan P, et al. Glucokinase as pancreatic beta cell glucose sensor and diabetes gene. J Clin Investig 1993; 92: 2092-2098.

13. Osbak KK, Colclough K, Saint-Martin C, et al. Update on mutations in glucokinase (GCK), which cause maturity-onset diabetes of the young, permanent neonatal diabetes, and hyperinsulinemic hypoglycemia. Hum Mutat 2009; 30: 1512-1526.

14. Velho G, Blanche H, Vaxillaire M, et al. Identification of 14 new glucokinase mutations and description of the clinical profile of 42 MODY-2 families. Diabetologia 1997; 40: 217-224.

15. Page RC, Hattersley AT, Levy JC, et al. Clinical characteristics of subjects with a missense mutation in glucokinase. Diabet Med 1995; 12: 209-217.

16. Page RC, Hattersley AT, Levy JC, et al. Clinical characteristics of subjects with a missense mutation in glucokinase. Diabet Med 1995; 12: 209-217.

17. Steele AM, Shields BM, Wensley KJ, et al. Prevalence of vascular complications among patients with glucokinase mutations and prolonged, mild hyperglycemia. JAMA 2014; 311: 279-286.

18. Jarrett RJ, McCartney P and Keen H. The Bedford Survey: ten year mortality rates in newly diagnosed diabetics, borderline diabetics and normoglycaemic controls and risk indices for coronary heart disease in borderline diabetics. Diabetologia 1982; 22: 79-84.

19. Hattersley AT, Turner RC, Permutt MA, et al. Linkage of type 2 diabetes to the glucokinase gene. Lancet 1992; 339: 1307-1310.

20. O'Rahilly S, Hattersley A, Vaag A, et al. Insulin resistance as the major cause of impaired glucose tolerance: a self-fulfilling prophesy? Lancet 1994; 344: 585-589.

21. Stride A, Vaxillaire M, Tuomi T, et al. The genetic abnormality in the beta cell determines the response to an oral glucose load. Diabetologia 2002; 45: 427-435.

22. Hattersley AT, Beards F, Ballantyne E, et al. Mutations in the glucokinase gene of the fetus result in reduced birth weight. Nat Genet 1998; 19: 268-270.

23. Velho G, Hattersley AT and Froguel P. Maternal diabetes alters birth weight in glucokinase-deficient (MODY2) kindred but has no influence on adult weight, height, insulin secretion or insulin sensitivity. Diabetologia 2000; 43: 1060-1063.

24. Spyer G, Hattersley AT, Sykes JE, et al. Influence of maternal and fetal glucokinase mutations in gestational diabetes. Am J Obstet Gynecol 2001; 185: 240-241.

25. Chakera AJ, Carleton VL, Ellard S, et al. Antenatal diagnosis of fetal genotype determines if maternal hyperglycemia due to a glucokinase mutation requires treatment. Diabetes Care 2012; 35: $1832-1834$

26. Shepherd M, Ellis I, Ahmad AM, et al. Predictive genetic testing in maturity-onset diabetes of the young (MODY). Diabet Med 2001; 18: 417-421.

27. McDonald TJ, Colclough K, Brown R, et al. Islet autoantibodies can discriminate maturity-onset diabetes of the young (MODY) from Type 1 diabetes. Diabet Med 2011; 28: 1028-1033.

28. Shields BM, McDonald TJ, Ellard S, et al. The development and validation of a clinical prediction model to determine the 
probability of MODY in patients with young-onset diabetes. Diabetologia 2012; 55: 1265-1272.

29. Owen KR, Thanabalasingham G, James TJ, et al. Assessment of high-sensitivity $\mathrm{C}$-reactive protein levels as diagnostic discriminator of maturity-onset diabetes of the young due to HNF1A mutations. Diabetes Care 2010; 33: 1919-1924.

30. McDonald TJ, McEneny J, Pearson ER, et al. Lipoprotein composition in HNF1A-MODY: differentiating between HNF1AMODY and type 2 diabetes. Clin Chim Acta 2012; 413: 927-932.

31. McDonald TJ, Shields BM, Lawry J, et al. High-sensitivity CRP discriminates HNF1A-MODY from other subtypes of diabetes. Diabetes Care 2011; 34: 1860-1862.

32. Bingham C, Ellard S, Nicholls AJ, et al. The generalized aminoaciduria seen in patients with hepatocyte nuclear factor-1alpha mutations is a feature of all patients with diabetes and is associated with glucosuria. Diabetes 2001; 50: 2047-2052.

33. Menzel R, Kaisaki PJ, Rjasanowski I, et al. A low renal threshold for glucose in diabetic patients with a mutation in the hepatocyte nuclear factor-1alpha (HNF-1alpha) gene. Diabet Med 1998; 15: 816-820.

34. Pontoglio M, Prie D, Cheret C, et al. HNF1 alpha controls renal glucose reabsorption in mouse and man. Embo Rep 2000; 1: 359-365.

35. Stride A, Ellard S, Clark P, et al. Beta-cell dysfunction insulin sensitivity, and glycosuria precede diabetes in hepatocyte nuclear factor-1alpha mutation carriers. Diabetes Care 2005; 28: 1751-1756.

36. Velho G, Vaxillaire M, Boccio V, et al. Diabetes complications in NIDDM kindreds linked to the MODY3 locus on chromosome 12q. Diabetes Care 1996; 19: 915-919.

37. Steele A, Hattersley A and Pearson E. Increased all-cause and cardiovascular mortality in MODY due to HNF-1alpha mutations. Diabet Med 2004; 21: 18.

38. Pearson ER, Liddell WG, Shepherd M, et al. Sensitivity to sulphonylureas in patients with hepatocyte nuclear factor-1alpha gene mutations: evidence for pharmacogenetics in diabetes. Diabetic Med 2000; 17: 543-545.

39. Shepherd M, Pearson ER, Houghton J, et al. No deterioration in glycemic control in HNF-1alpha maturity-onset diabetes of the young following transfer from long-term insulin to sulphonylureas. Diabetes Care 2003; 26: 3191-3192.

40. Shepherd M and Hattersley AT. 'I don't feel like a diabetic any more': the impact of stopping insulin in patients with maturity onset diabetes of the young following genetic testing. Clin Med 2004; 4: 144-147.

41. Katra B, Klupa T, Skupien J, et al. Dipeptidyl peptidase-IV inhibitors are efficient adjunct therapy in HNF1A maturity-onset diabetes of the young patients-report of two cases. Diabet Technol Ther 2010; 12: 313-316.

42. Lumb AN and Gallen IW. Treatment of HNF1-alpha MODY with the DPP-4 inhibitor Sitagliptin(1). Diabet Med 2009; 26: 189-190.

43. Reznik Y, Dao T, Coutant R, et al. Hepatocyte nuclear factor-1 alpha gene inactivation: cosegregation between liver adenomatosis and diabetes phenotypes in two maturity-onset diabetes of the young (MODY)3 families. J Clin Endocrinol Metab 2004; 89: 1476-1480.

44. Pearson ER, Boj SF, Steele AM, et al. Macrosomia and hyperinsulinaemic hypoglycaemia in patients with heterozygous mutations in the HNF4A gene. PLoS Med 2007; 4: e118.

45. Kapoor RR, Locke J, Colclough K, et al. Persistent hyperinsulinemic hypoglycemia and maturity-onset diabetes of the young due to heterozygous HNF4A mutations. Diabetes 2008; 57: 1659-1663.

46. Bingham C, Ellard S, Cole TR, et al. Solitary functioning kidney and diverse genital tract malformations associated with hepatocyte nuclear factor-1beta mutations. Kidney Int 2002; 61: 1243-1251.

47. Edghill EL, Bingham C, Ellard S, et al. Mutations in hepatocyte nuclear factor-1 1 beta\} and their related phenotypes. J Med Genet 2006; 43(1): 84-90.

48. Oram RA, Edghill EL, Blackman J, et al. Mutations in the hepatocyte nuclear factor-1beta (HNF1B) gene are common with combined uterine and renal malformations but are not found with isolated uterine malformations. Am J Obstet Gynecol 2010; 203: $364 \mathrm{e} 1-5$.

49. Murphy R, Turnbull DM, Walker M, et al. Clinical features, diagnosis and management of maternally inherited diabetes and deafness (MIDD) associated with the $3243 \mathrm{~A}>\mathrm{G}$ mitochondrial point mutation. Diabet Med 2008; 25: 383-399.

50. Narbonne H, Perucca-Lostanlen D, et al. Searching for A3243G mitochondrial DNA mutation in buccal mucosa in order to improve the screening of patients with mitochondrial diabetes. Eur J Endocrinol 2001; 145: 541-542.

51. McDonnell M, Schaefer A, Blakely E, et al. Noninvasive diagnosis of the $3243 \mathrm{~A}>\mathrm{G}$ mitochondrial DNA mutation using urinary epithelial cells. Eur J Hum Genet 2004; 12: 778-781.

52. Suzuki S, Hinokio Y, Ohtomo M, et al. The effects of coenzyme Q10 treatment on maternally inherited diabetes mellitus and deafness, and mitochondrial DNA 3243 (A to G) mutation. Diabetologia 1998; 41: 584-588.

53. Say RE, Whittaker RG, Turnbull HE, et al. Mitochondrial disease in pregnancy: a systematic review. Obstet Med 2011; 4: 90-94.

54. Hosono T, Suzuki M and Chiba Y. Contraindication of magnesium sulfate in a pregnancy complicated with late-onset diabetes mellitus and sensory deafness due to mitochondrial myopathy. J Matern Fetal Med 2001; 10: 355-356. 